\title{
Low Power and High Performance MTCMOS Conditional Discharge Flip Flop
}

\author{
Karthik. B, Sriram. M, Jasmin. M.
}

\begin{abstract}
Utilization in high-performance integrated circuits has been one of the most severe limitations in models in recent years.. Conditional discharge flip flop (CDFF) related to one of the earliest pulses caused flipflop reduces internal switching activities as that of existing explicit pulse triggered Data close to output flipflop (Ep-DCO). Registers are the main parts for processing information eg: in counters, accumulators etc.,. Implementation of these registers using CDFF can achieve low power consumption and high performance. MTCMOS (multi threshold CMOS) technique saves the leakage power during standby mode operations and hence, enhances the circuit performance for long battery life applications. We find that, using both MTCMOS and conditional discharge technique in flip flop, improves the performance and also consumes low power. In this paper, we simulate CDFF and the proposed MTCMOS CDFF to prove that MTCMOS CDFF is the best among the fastest pulse triggered flipflops. We also implement an application 4 bit shift register using proposed MTCMOS conditional discharge flip flop.

Keywords : Conditional discharge flip flop (CDFF); explicit pulsed data close to output flip flop (ep-DCO); MTCMOS technique
\end{abstract}

\section{INTRODUCTION}

Mostly power consumption in dynamic flip-flops occurs due to the internal node switching activities. These switching because of the precharge and discharge paths being opened during the input and output state changes. Many techniques were proposed to reduce these internal node switching activities [1]. They are conditional precharge, conditional capture and conditional discharge techniques [2]. As compared to all the three techniques, conditional discharge technique is the most efficient and complexity of the circuit is less. In this paper we implement two types of double edge triggered, explicit pulsed flip-flops namely,

1. Explicit pulsed data close to output flipflop

2. Conditional discharge flipflop.

The comparison is also done. In both the flip-flops explicit pulse triggering allows us for double edge triggering and also power sharing among multiple flip flops. The clock switching activity is hence reduced .In section II, we explain the concept of ep-DCO flip flop. In section III, we explain the concept of CDFF with and without MTCMOS technique is communicated. In part IV, we discuss simulation outcomes and comparisons ep-DCO and CDFF flip flops. In section V,

Revised Manuscript Received on August 22, 2019.

Karthik.B Assistant Professor, Department of Electronics And Communication Engineering,, Bharath Institute of Higher Education and Research, Chennai, India . karthik.ece@bharathuniv.ac.in

Sriram.M, Assistant Professor, Department of Electronics And Communication Engineering,, Bharath Institute of Higher Education and Research, Chennai, India msr1sriram@gmail.com

Jasmin.M, Assistant Professor, Department of Electronics And Communication Engineering,, Bharath Institute of Higher Education and Research, Chennai, India. implementation of 4 bit shift registers using CDFF and its power comparison with and without MTCMOS. Section V follows conclusion.

\section{EXPLICIT PULSE TRIGGERED FLIPFLOP}

One illustration of explicit pulse brought on flip-flop (ep-FF) is the express pulsed data close to output (ep-DCO) Flip-flop; it's considered probably the fastest flip-flops as a result of its semi-dynamic constitution. It's right fitted to very excessive-overall performance features[3], in which it is able to be employed within the maximum important Paths of design to achieve a very tiny flip-flop to enlarge. This makes it feasible for additional liberty in cycle budgeting, especially with its terrible setup time function, due to the use of the heart beat trigger mechanism. Fig. Fig. 1 is the ep-DCO flip-flop schematic; its semi-dynamic charter consists of the following levels: dynamic (first phase) and static (second stage).

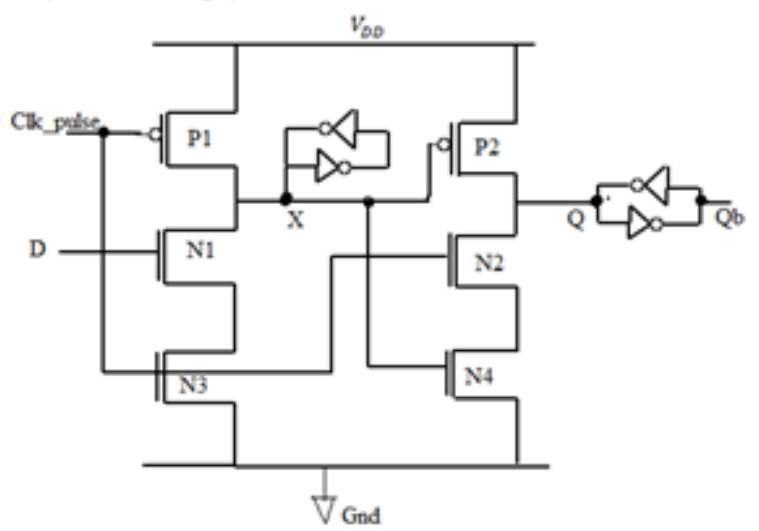

Fig. 1. Double edge triggered explicit-pulsed flipflop (ep-DCO flipflop).

A) Principle of operation of explicit pulsed data close to Output (ep-DCO) flipflop\

From Fig. 1, we find that on the rising fringe of the clock transistors N2 and N3 activate for a short interval of time, which is the same as the extend incurred through the heartbeat generator. For the duration of this interval, The flip flop is evident and the input data spreads to the throughput. After a deceptive period, pull down the routes in each level is turned off via the equal transistors $\mathrm{N} 2$ and $\mathrm{N} 3$. The double edge triggering clock pulse is generated and given as input to the clocked transistors $\mathrm{P} 1, \mathrm{~N} 2$, and N3 by a pulse generator as shown in Fig. 2

Thus any alternate on the enter aren't capable of Just go to the output. Midfielders are used to conserve the output and inner module states while the transistor is in the maintenance mode. Careful assessment of 
the ep-DCO circuit famous an enormous quantity of energy Consume by charging and unloading the indoor node $\mathrm{X}$ through the P1 transistor, which does so substantially during each clock cycle, while input D does not change. Additionally, while the output is excessive, the re-charging / discharging of node $\mathrm{X}$ causes system faults in each clock cycle to expose the output. These machine faults spread to the pushed doors. now not handiest to broaden their switching vigor intake however also to motive noise troubles so one can cause System misfiring.

\section{CONDITIONAL DISCHARGE FLIP FLOP}

The flip-flop structure used right here is identical as the express pulsed knowledge just about output (ep-DCO) semi dynamic structure. The schematic diagram of the proposed Dishonorable discharge flip flop (CDFF) is shown in Fig. Three of them. Uses the phototransistor as shown in Fig. 2. For double-edge ignition or testing. The flip-flop is made up of two stages. Stage one is responsible for shooting down the low-to-high transition. Stage 2 is accountable for capturing the high-to-low transition.[3]Principle of operation of conditional discharge flipflop (CDFF) When D input switches from low to high, initially $\mathrm{X}$ is precharged to Vdd and output $(\mathrm{Q}, \mathrm{Qb})$ are (low, high). When D is at high transistor N1, N3, N5 transistors are on and X discharges through N1, N3, and N5 to ground. Then Output Q charges to Vdd through P2. The Transistor N4 is OFF and output Q stays high as long as D input stays high. Internal node $\mathrm{X}$ is again recharged to as discharge path at dynamic stage shuts off by the Qb. When D input switches from high to low, as D goes for high to low transition, the transistor N4 is ON due to $\mathrm{Y}$ becomes high. The discharge path is $\mathrm{ON}$ and output $\mathrm{Q}$ is discharged to ground through N2 and N4. Thus output Q captures high to low transition. $\mathrm{X}$ remains in its precharged state as $\mathrm{N} 1$ turns off due to D input.[4]

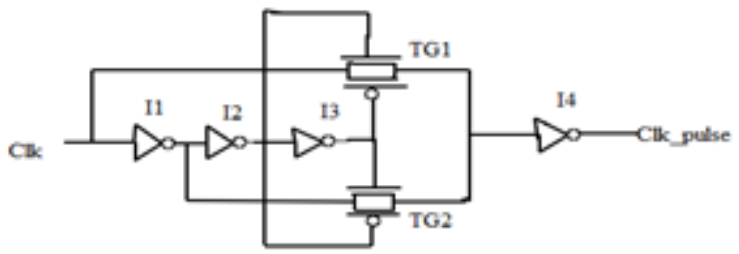

Fig. 2. Clock pulse generator used for Double edge triggering

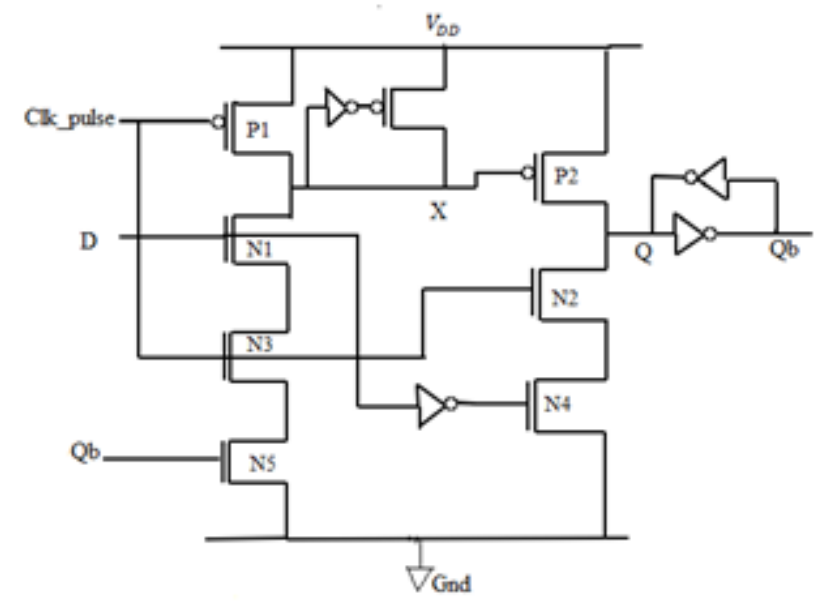

Fig. 3. Conditional Discharge Double-edge triggered Flipflop

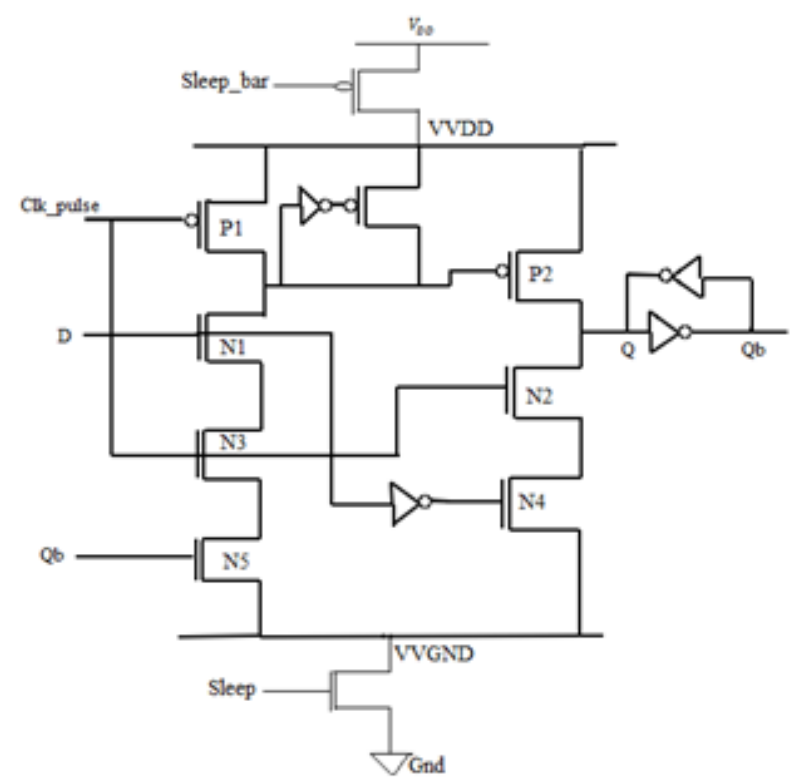

Fig. 4. Conditional Discharge Flipflop with MTCMOS technique

Due to the fact that node $\mathrm{X}$ shouldn't be discharged and charged each clock cycle, no glitches appear on the output node $\mathrm{Q}$ when the input $\mathrm{D}$ stays excessive, and $\mathrm{Q}$ will not be discharged at the establishing of every valuation. For that reason, CDFF elements much less switching noise new release. Additionally, node $\mathrm{X}$ stays excessive or recharged quite often, which helps in shortening the keeper constitution as shown in Fig. 3. Additionally, clock gating may also be with ease applied to do away with power consumption when input D keeps the identical value. This conditional discharge flip flop can be modified using MTCMOS (multi threshold CMOS) technique [2] as shown in Fig. 4 for reducing the standby power. The transistors with thin lines are the sleep transistors. These sleep transistors are used in the MTCMOS technique for reducing the sub threshold leakage currents when the circuit is not in use. These sleep transistors can be controlled for further reducing the standby power i.e., when input and output are in same state and the circuit can be disabled by using the sleep signals. The transistors other than sleep transistors are given low threshold voltage, for high speed operation. 
The sleep transistors are to be sized optimally to overcome delay and area penalties. We chose threshold voltages for high transistors are $0.6 \mathrm{~V}$ and $-0.6 \mathrm{~V}$ and for low transistors as $0.3 \mathrm{~V}$ and $-0.32 \mathrm{~V}$ for NMOS and PMOS respectively. [5]

\section{COMPARISON OF EP-DCO AND CDFF}

The modeling result for all Flip-flops was purchased in a $0.18 \mu \mathrm{m}$ CMOS study at room temperature using HSPICE, the output voltage is 1.Eight V. Alternatively, a clock speed of $125 \mathrm{MHz}$ is used. of $250 \mathrm{MHz}$ used in single part triggered Flip-flops. The upward push time and fall time of the clock are stored at 100ps. for both the flip-flops are kept at $22.08 \mathrm{fF}$. The is the load of 4 cascade flip-flops used for constructing a 4-bit register.[6] It has been observed that in fig 7, the output wave form ep-DCO flip flop a lot of node X shifting activity occurs when D is stable High. This is due to the simultaneous precharging and discharging of node $\mathrm{X}$ at every clock cycle. Also some glitches appear at the output Q. These glitches increases power consumption of the circuit. In Fig. 9 we observe the output wave form of MTCMOS CDFF which is also same as CDFF with reduced glitches as compared to ep-DCO flip flop at node $\mathrm{Q}$ because of reduced internal switching activities at node $\mathrm{X}$. As the discharge path is controlled by the output $\mathrm{Qb}$ in CDFF which avoids the simultaneous charging and discharging of internal node $X$. It is observed that Power consumption is abridged as evaluated to ep-DCO flip flop as glitches at the output Q are reduced when D input stays High.[7]

\section{A.Power Consumption Comparison of Ep-DCO and CDFF}

In table I, we compare total average power consumed including the clock pulse generator power by the explicit pulsed data close to output flip flop (ep-DCO) and the conditional discharge flipflop.[8] Conditional discharge Flip flop achieves low power and high performance with less energy consumption and high speed. The ep-DCO consumes more power dissipation is because of the glitches in the output. And also, CDFF with MTCMOS technique achieves power delay product approximately equal to CDFF. So, it's better to use MTCMOS technique for reducing stand by leakage power consumption.[9]

TABLE I. Power and delay comparison of flip flops

\begin{tabular}{|c|l|l|l|}
\hline & Delay & $\begin{array}{c}\text { Total average } \\
\text { power } \\
\text { consumed }\end{array}$ & $\begin{array}{c}\text { Power } \\
\text { Delay } \\
\text { product }\end{array}$ \\
\hline Ep-DCO & $216 \mathrm{ps}$ & $80.67 \mu \mathrm{w}$ & $17.280 \mathrm{fJ}$ \\
\hline CDFF & $223 \mathrm{ps}$ & $77.199 \mu \mathrm{w}$ & $17.17 \mathrm{fJ}$ \\
\hline $\begin{array}{c}\text { MTCMOS } \\
\text { CDFF }\end{array}$ & $236 \mathrm{ps}$ & $71.49 \mu \mathrm{w}$ & $16.7 \mathrm{fJ}$ \\
\hline
\end{tabular}

From the fig 6, from the chart it is observed that even though the delay of the MTCMOS CDFF is increasing the increase in the power delay product curve is below the CDFF and EPDCO flip-flops curves. Thus this shows that MTCMOS $\mathrm{CDFF}$ is the best in achieving low power and also high performance.[10]

\section{V.BIT SHIFT REGISTER IMPLEMENTATION USING MTCMOS CDFF}

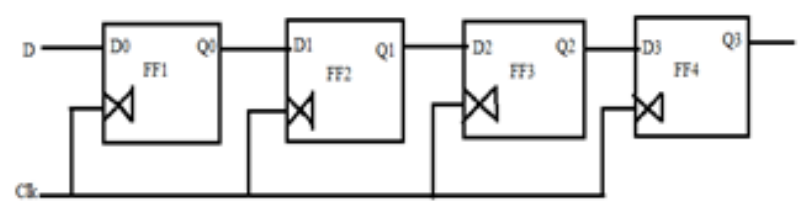

Fig. 5. 4 Implementation of the Bit Shift Register using the suggested flip flops

Fig. 5 is the implementation of 4 bit shift register implementation using double edge triggered conditional discharge flip flop (CDFF). This can also be implemented using proposed MTCMOS CDFF. One set of sleep transistors (PMOS and NMOS) are enough for all the flip-flops in the four bit register to control the circuit instead of placing sleep transistors separately for each and every CDFF. In this way we can save the area. Table II is the power consumption comparison of CDFF with and without MTCMOS technique. It is observed that usage of MTCMOS CDFF saves $18 \%$ of power consumed as that of conventional CDFF.[11]

TABLE II. Comparison of 4bit shift register

\begin{tabular}{|c|c|}
\hline \multicolumn{2}{|c|}{ TABLE II. Comparison of 4 bit shift register } \\
\hline Type & $\begin{array}{c}\text { Total average power } \\
\text { consumed at } 250 \mathrm{MHz}\end{array}$ \\
\hline Ep-DCO & $165 \mu \mathrm{w}$ \\
\hline CDFF & $152.17 \mu \mathrm{w}$ \\
\hline CDFF(MTCMOS) & $128.18 \mu \mathrm{w}$ \\
\hline
\end{tabular}

The power compared also includes the clock pulse generator power which is shared among the flip flops. In Fig. 10 we observe the shift operation of data of a 4 bit shift register using MTMCOS CDFF. This four bit shift register can be used to implement a low power and high performance linear feedback shift register (LFSR) for cryptography and is also valuable as evaluated to gray and binary counter and diversity of other applications.[12-20]

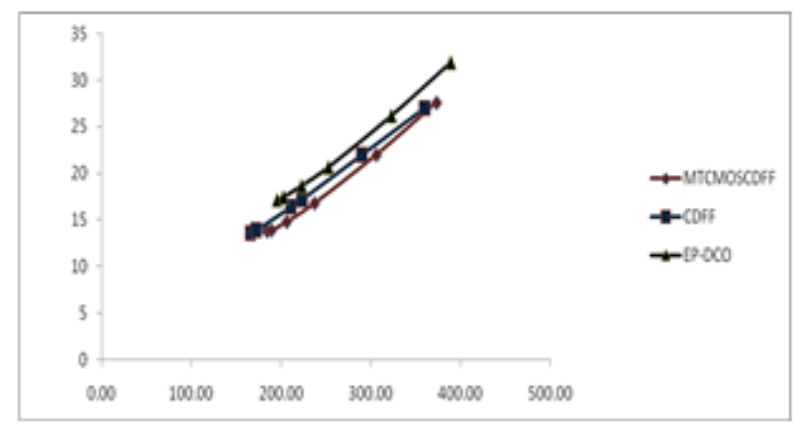

Fig. 6. Hspice simulated output wave forms of CDFF flip flop 


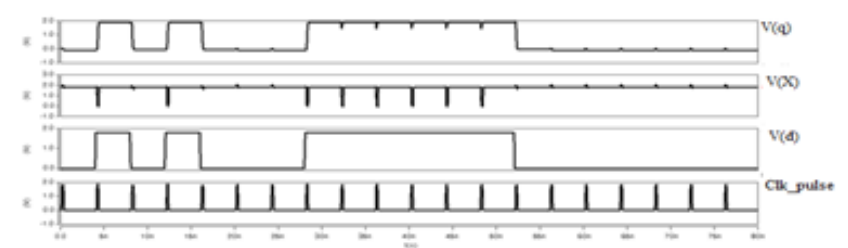

Fig. 7. Hspice simulated output wave form of EP-DCO flip flop

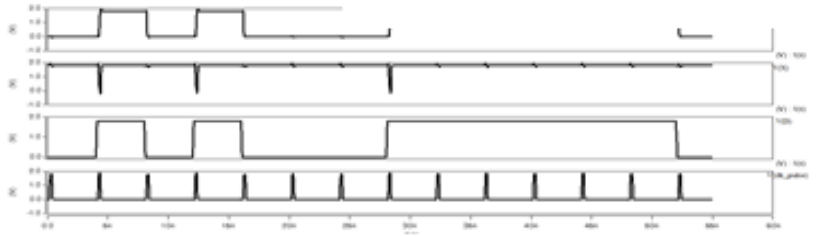

Fig. 8. Hspice simulated output wave form of CDFF flip flop

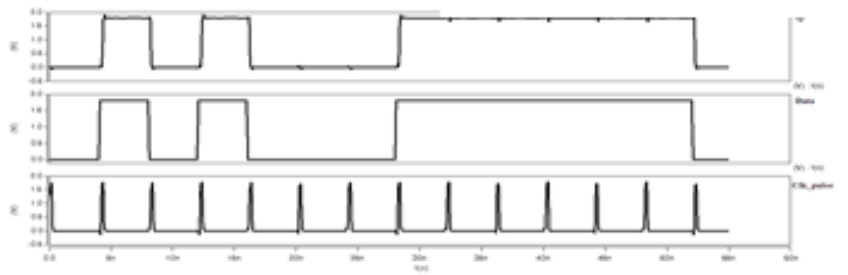

\section{Fig.9 Hspice simulated output wave form of MTCMOS} CDFF flip flop

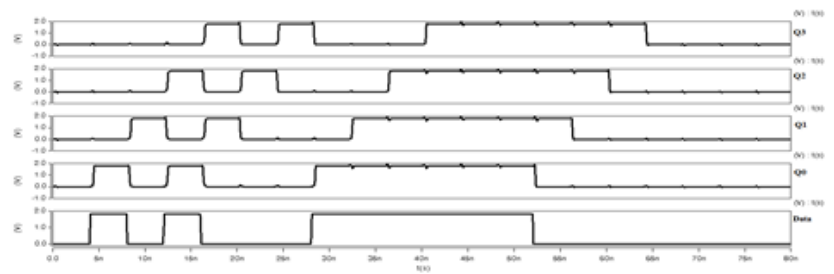

Fig.10. 4 bit shift register output of MTCMOS CDFF flip flop

\section{CONCLUSION}

In this manuscript, MTCMOS technique is introduced in conditional discharge flip-flop to reduce the internal node switching activities and also the leakage power. While ep-DCO is suitable for critical pathways, CDFF is suitable for both mode-insensitive pathways and rate-critical pathways for energy effectiveness.. In terms of Power Delay Product, ep-DCO CDFF outperforms, Conditional Precharge Flip flops and conditional capture. The CDFF with MTCMOS technique is the best to use in registers and counter applications.

\section{REFERENCES}

1. Kongkham, D. \& Sundararajan, M. 2019, "Distributed wideband sensing method for faded dynamic spectrum access", International Journal of Innovative Technology and Exploring Engineering, vol. 8, no. 10, pp. 4309-4312.

2. Balaji, S., John Paul Praveen, A. \& Mohanraj, R. 2019, "Recognizable proof and analysis of palm print in biometric authentication system using bayes techniques", International Journal of Innovative Technology and Exploring Engineering, vol. 8, no. 9 Special Issue 3, pp. 1126-1129.

3. Kavitha, G., Priya, N., Velvizhi, R. \& Allin Geo, A.V. 2019, "Parallel computation in correspondence and signal processing", International Journal of Innovative Technology and Exploring Engineering, vol. 8, no. 9 Special Issue 3, pp. 1136-1139.
4. Hema, R., Sundararajan, M. \& Balaji, S. 2019, "Smartphone control robot with automatic firing gun", International Journal of Innovative Technology and Exploring Engineering, vol. 8, no. 9 Special Issue 3, pp. 625-627.

5. Kaliyamurthie, K.P., Sundar Raj, B., Velvizhi, R. \& Shanmugapriya, K. 2019, "Dual band paper substrate CPW antenna for wireless applications", International Journal of Innovative Technology and Exploring Engineering, vol. 8, no. 9 Special Issue 3, pp. 605-608.

6. Geo, A.V.A., Arunachalam, A.R., Michael, G. \& Elankavi, R. 2019, "Evaluating architecture using compact modalities", International Journal of Innovative Technology and Exploring Engineering, vol. 8, no. 9 Special Issue 3, pp. 836-838.

7. Theivasigamani, S., Jeyapriya, D. \& Anita Davamani, K. 2019 "Anamoly analyzing and exploring for wireless sensor networks", International Journal of Innovative Technology and Exploring Engineering, vol. 8, no. 9 Special Issue 3, pp. 1116-1118.

8. Jeyapriya, D., Theivasigamani, S., Velvizhi, R. \& Nandhini, P. 2019, "Program detection in wireless feeler networks", International Journal of Innovative Technology and Exploring Engineering, vol. 8, no. 9 Special Issue 3, pp. 1194-1195.

9. Gowri Sankaran, B., Karthik, B. \& Vijayaragavan, S.P. 2019, "Image compression utilizing wavelet transform", International Journal of Innovative Technology and Exploring Engineering, vol. 8, no. 10, pp. 4305-4308.

10. Gowri Sankaran, B., Karthik, B. \& Vijayaragavan, S.P. 2019, "Weight ward change region plummeting change for square based image huffman coding", International Journal of Innovative Technology and Exploring Engineering, vol. 8, no. 10, pp. 4313-4316.

11. Hema, R., Sundararajan, M. \& Balaji, S. 2019, "Smartphone control robot with automatic firing gun", International Journal of Innovative Technology and Exploring Engineering, vol. 8, no. 9 Special Issue 3, pp. 625-627.

12. Rangaswamy, K. \& Rajabhushanam, C. 2019, "Congestion control in wireless network using TCP friendly rate control (TFRC)", International Journal of Recent Technology and Engineering, vol. 8, no. 2 Special issue 3, pp. 1598-1602.

13. Tamil Selvan, S. \& Sundararajan, M. 2019, "Performance Parameters of 3 Value 8t Cntfet Based Sram Cell Design Using H-Spice", International Journal of Recent Technology and Engineering, vol. 8, no. 2 Special issue 5, pp. 22-27.

14. Vinoth, V.V. \& Kanniga, E. 2019, "Steganographical techniques in hiding text images - system", International Journal of Recent Technology and Engineering, vol. 8, no. 2, pp. 6535-6537.

15. Saravana, S., Balaji, S., Arulselvi, S. \& John Paul Praveen, A. 2019, "Reliable power quality monitoring and protection system", International Journal of Innovative Technology and Exploring Engineering, vol. 8, no. 9 Special Issue 3, pp. 644-645.

16. Sundaramoorthy, A. \& John Wiselin, M.C. 2019, "Single patch antenna with multiple feed", International Journal of Innovative Technology and Exploring Engineering, vol. 8, no. 9, pp. 1743-1747.

17. Velavan, R., Bharanidharan, S. \& Sheeba, B. 2019, "EMF pollution Causes, effects and protection", International Journal of Innovative Technology and Exploring Engineering, vol. 8, no. 9 Special Issue 3, pp. 1166-1168.

18. Veer, R.A., Arulselvi, S. \& Karthik, B. 2019, "Construction of ensemble square classification approaches in MIMO OFDM", International Journal of Engineering and Advanced Technology, vol. 8, no. 5, pp. 2039-2041.

19. Agitha, W. \& Kaliyamurthie, K.P. 2019, "Improved energy efficient in WBAN using MAC with cloud computing", International Journal of Innovative Technology and Exploring Engineering, vol. 8, no. 8, pp. 2405-2408.

20. Kastro, G.G. \& Wiselin, M.C.J. 2019, "Design and analysis of stub loaded resonator", International Journal of Recent Technology and Engineering, vol. 8, no. 1 Special Issue4, pp. 272-283. 


\section{AUTHORS PROFILE}

Karthik.B Assistant Professor, Department of Electronics And Communication Engineering,, Bharath Institute of Higher Education and Research, Chennai, India

Sriram.M, Assistant Professor, Department of Electronics And Communication Engineering,, Bharath Institute of Higher Education and Research, Chennai, India

Jasmin.M, Assistant Professor, Department of Electronics And Communication Engineering,, Bharath Institute of Higher Education and Research, Chennai, India. 